\title{
DỨBin
}

Technological University Dublin

ARROW@TU Dublin

Articles

2020

\section{Finite Element Simulation of Head Impacts in Mixed Martial Arts}

Stephen Tiernan

Technological University Dublin, stephen.tiernan@tudublin.ie

Aidan Meagher

Technological University Dublin

David O'Sullivan Dr

Pusan National University, davidosullivan@pusan.ac.kr

See next page for additional authors

Follow this and additional works at: https://arrow.tudublin.ie/creaart

Part of the Biomechanics and Biotransport Commons, and the Other Biomedical Engineering and Bioengineering Commons

\section{Recommended Citation}

Stephen Tiernan, Aidan Meagher, David O'Sullivan \& Eoin O'Kelly (2021) Finite element simulation of head impacts in mixed martial arts, Computer Methods in Biomechanics and Biomedical Engineering, 24:3,

278-288, DOI: 10.1080/10255842.2020.1826457

This Article is brought to you for free and open access by ARROW@TU Dublin. It has been accepted for inclusion in Articles by an authorized administrator of ARROW@TU

Dublin. For more information, please contact arrow.admin@tudublin.ie, aisling.coyne@tudublin.ie, gerard.connolly@tudublin.ie.

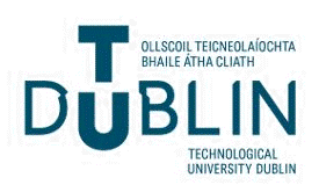


Authors

Stephen Tiernan, Aidan Meagher, David O'Sullivan Dr, and Eoin O'Kelly Dr

This article is available at ARROW@TU Dublin: https://arrow.tudublin.ie/creaart/9 


\section{Finite Element Simulation of Head Impacts in Mixed Martial Arts}

Stephen Tiernan ${ }^{1 *}$, Aidan Meagher ${ }^{1}$, David O’Sullivan ${ }^{2}$, Eoin O’Kelly ${ }^{3}$

Affiliation:

${ }^{1}$ Technological University Dublin

${ }^{2}$ Pusan National University, Division of Sports Science, Busan, Republic of Korea

${ }^{3}$ Department of Neurology, Health Care Centre, Hospital 5, St James's Hospital, Dublin 8, Ireland.

* Corresponding Author

Corresponding Author: Stephen Tiernan, Technological University Dublin, Tallaght Campus, Dublin 24, Ireland.

Email: stephen.tiernan@tudublin.ie 


\begin{abstract}
This study determined brain stress and strain in an unhelmeted sport and correlated this with concussive injuries. Thirteen MMA athletes were fitted with the MiG2.0 Stanford instrumented mouthguard. The mouthguard records linear acceleration and angular velocity in 6 degrees of freedom. Angular acceleration was calculated by differentiation. All events were video recorded, time stamped and reported impacts confirmed. 298 impacts above 10g were recorded during sparring sessions and 153 impacts in competitive events. The competitive events resulted in five concussions which were diagnosed by a medical doctor. The impact with the highest angular acceleration from each sparring session and competitive event was simulated using the GHBMC head and neck model. The model was run on Amazon Web Services using the LS-Dyna explicit solver. The resultant linear acceleration, strain in the corpus callosum and brain stem and shear stress in the corpus callosum were all significantly different in concussed athletes compared to uninjured. Average strain in the corpus callosum of concussed fighters was 0.27 which was $87.9 \%$ higher than uninjured fighters and was the best strain indicator of concussion. The best overall predictor of concussion found in this study was shear stress in the corpus callosum which differed by $111.4 \%$ between concussed and uninjured athletes. This study is unique in that it measured head accelerations in vivo and determined that high stress and strain in the corpus callosum correlated with the concussive injuries.
\end{abstract}

Keywords: Concussion, Maximum principal strain, corpus callosum 


\section{Introduction}

Concussion in sport is very prevalent with between 1.6 and 3.8 million sports-related concussions in the United States each year (Langlois et al. 2006). The diagnosis of concussion is particularly difficult with many studies reporting that approximately $50 \%$ of concussions go unreported (Elliott et al. 2015). To aid with the diagnosis of concussion researchers have sought to identify parameters that will indicate if an athlete has suffered from a head injury. Parameters that have been investigated include kinematic measures, bloød bio-markers, rapid eye movement measurements and brain tissue criteria.

The relationship between head kinematics and concussion in US football has been extensively studied as it has been possible to mount sensors within the helmet to capture acceleration data. The Head Impact Telemetry System (HITS), Simbex, Lebanon, NH, USA, was developed in 2002 and uses an array of accelerometers to measure linear and rotational accelerations. The alternative to measuring head accelerations in vivo is to recreate the impact using video data in a laboratory or with kinematic software. Several video angles are required for this to be successful and it is a difficult and time consuming task with up to $25 \%$ angular acceleration errors (Newman et al. 2005).

To address these errors and to enable the measurement of head accelerations in vivo instrumented mouthguards have been developed. Hernandez et al. recorded two concussions in US football using an instrumented mouthguard, one case involved a loss of consciousness and the other was self-reported (Hernandez et al. 2015). King at al used the X2 BioSystems mouthguard to record over 20,000 impacts above $10 \mathrm{~g}$ in amateur rugby but no head injuries were sustained (King et al. 2014). A skin patch sensors was developed by X2 BioSystems and has been used in stulies of heal impacts in rugby (King et al. 2016), US football unhelmeted practice (McCuen et al. 2015, Swartz et al. 2015), Australian football (Hecimovich et al. 2018) 
and Taekwondo (O'Sullivan 2014) although none of these studies included a concussive injury.

It has been reported that the angular acceleration recorded by the skin patch senser is underestimated by up to 25\% (Nevins et a1. 2015). One of the few studies to report concussions in an unhelmeted sport was carried out by McIntosh et al. who used simulation software to recreate impacts in Australian rules football and rugby (McIntosh et al. 2014). The study recreated 27 concussive impacts and determined that the mean linear and angular accelerations for the injury cases were $103.4 \mathrm{~g}( \pm 29.5 \mathrm{~g})$ and $7951 \mathrm{rad} / \mathrm{s}^{2}\left( \pm 3562 \mathrm{rad} / \mathrm{s}^{2}\right)$, respectively.

The only known studies to report in vivo unhelmeted head accelerations that have resulted in a concussion have used data from the study of head impacts in Mixed Martial Arts (MMA) reported in this paper. The first of these studies included rugby players and MMA athletes and investigated the correlation of strain with disruption to the blood brain barrier (O'Keeffe et al. 2019). The second developed a multi-directional dynamic model of the head and investigated it's reliability in predicting head injury (Laksari et al. 2019). Laksari's study found that peak angular acceleration was the best predictor of head injury in cases of high angular acceleration and low velocity.

In 1943 Holburn first proposed that concussion was caused by angular velocity and acceleration rather than linear acceleration (Holbourn 1943). Since then animal studies have found that linear head accelerations are important for focal trauma but angular accelerations cause inertial loading of the brain and correlate with brain trauma severity (Raghupathi et al. 2004, Gennarellie 1983, Ommaya \& Gennarelli 1974). In a study of 300,977 impacts in US football which included 57 concussions an angular acceleration of $6383 \mathrm{rad} / \mathrm{s}^{2}$ was found to represent a 50\% risk of concussion (Rowson et al. 2012). The magnitude of the change in angular velocity, and hence high angular acceleration has been shown to correlate with brain strain (Kleiven 2005). 
Simulation studies play a unique role in head impact investigations as they enable the determination of brain tissue stress and strain resulting from trauma. The Wayne state head model is one of the most detailed head models and is capable of simulating impacts up to $200 \mathrm{~g}$ and $12 \mathrm{krad} / \mathrm{s}^{2}$ (Zhang et al. 2001). This model was used to investigate concussion and determined that the largest strains occurred in the fornix, mid-brain and corpus callosum and that there was a significant correlation between strain and concussive symptoms (Viano et al. 2005). Kleiven et al found lateral angular accelerations (in the coronal plane) gave rise to higher strains than impacts from other directions (Kleiven 2005). Generally, kinematic data is used to define the boundary conditions for simulation models. In order to quantify the kinematics of head impacts in US football Newman et al. recreated 27 impacts in a laboratory (Newman et al. 2000). Several researchers have used this data with simulation models to find the average strain in various brain regions of concussed players or the strain that related to a $50 \%$ probability of concussion. A 50\% probability of concussion in US football has been reported for strains in the corpus callosum of 0.13 (Giordano \& Kleiven 2014) to 0.21 (Kleiven 2007). The average strain in the corpus callosum of concussed Australian rules football and rugby players was 0.31 (Patton et al. 2013, McIntosh et al. 2014). High strains in the corpus callosum are thought to be due to lateral distortions of the falx, caused by high coronal angular accelerations (Ho et al. 2017).

Strain rate has also been found to be associated with the risk of concussion. Strain rates of $48.5 \mathrm{~s}^{-1}$ (Kleiven 2007) and $60 \mathrm{~s}^{-1}$ (Zhang et al. 2003) have been related to a 50\% probability of concussion.

\section{Mixed Martial Arts}

Mixed martial arts (MMA) is a competitive, full-contact sport that involves an amalgamation of elements drawn from boxing, wrestling, karate, taekwondo, jujitsu, muay thai, judo, and 
kickboxing (Hutchison et al. 2014). The fighters wear $110 \mathrm{~g}$ to $170 \mathrm{~g}$ gloves and do not wear head protection. Competitive bouts consist of 3 rounds of 5 minutes each, provided the referee doesn't stop the fight. Fights are ended by the referee either due to a knockout (KO), where there is a loss of consciousness, or more commonly a technical knockout (TKO), where a fighter appears unable to defend themselves. The fight may also end by submission. A tenyear review of injuries in MMA found that head trauma was the most common reason for match stoppages (28.3\%) (Buse 2006).

\section{Method}

Thirteen adult MMA fighters took part in the study, 12 professional or semi-professional and 1 amateur. Fighters took part in both sparring and competitive events, as shown in Table 1 . The fighters were fitted with the Stanford instrumented mouthguard (MiG2.0) and ethical approval was granted by the Technological University Dublin, Tallaght Campus, Ethics committee REC-STF1-201819.

[Table 1 near here]

The Stanford instrumented mouthguard has previously been used in studies of head impacts primarily in US football (Hernandez et al. 2015). The mouthguard has a triaxial accelerometer and a triaxial gyroscope to measure angular rate. The sensors, processor and battery are completely sealed in three layers of ethylene vinyl acetate in a dental moulded mouthguard. Data is downloaded from the device post-event via Bluetooth (Kuo et al. 2016). In this study impacts were recorded when linear accelerations exceeded the $10 \mathrm{~g}$ threshold established in previously published studies (King et al. 2015). The acquisition window was 50ms pre-trigger and $150 \mathrm{~ms}$ post-trigger. Linear acceleration and angular velocity were sampled at $1000 \mathrm{~Hz}$ and all data was filtered using a 4th order Butterworth low-pass filter with a cut-off frequency of 300Hz. Angular acceleration was estimated using a 5-point stencil derivative of the measured 
angular velocity (Wu et al. 2016). The accelerations were transformed to the center of gravity using the offsets for a $50^{\text {th }}$ percentile human head. A normalized root mean square error of $15 \%$ has been reported for the kinematic measurements recorded by the Stanford mouthguard (Kuo et al. 2016). A sample of the data from one impact recorded during a sparring session is shown in Figure 1.

[Figure 1 near here]

$\underline{\text { In order to validate the mouthguard data each event was video recorded by two cameras at } 60}$ frames per second. The cameras were placed around the arena at approximately 90 degrees to each other. Each event was recorded by two cameras at 60 frames per second. The cameras were placed around the arena, at approximately 90 degrees to each other. In addition, TV coverage was available for the competitive events. The time on the mouthguard data was aligned with the video time line and the video was examined frame by frame by two researchers using Kinovea video analysis software. The video data was used to confirm that a head impact had occurred and that the direction of the impact conformed to the direction indicated by the mouthguard. If an impact could not be confirmed using the video data, it was removed from the data set.

The MMA athletes were medically examined before the study commenced, immediately after competitive bouts and again approximately 48 hours after the competitive events. The impact with the highest resultant angular acceleration from each event was simulated.

\section{Simulation}

The Global Human Body Model Consortium (GHBMC) is a multi-institutional organization created in 2006 that includes 6 universities and 8 automotive manufacturers. The organization aims to produce the most biofidelic simulation body model. The model head was developed by Wayne State University, the neck by the University of Waterloo, and the thorax and pelvis by 
the University of Virginia. The model is available to researchers under license from Elemance Ltd., USA. This study used the head and neck portion of the GHBMC which consists of 532,608 elements and 426 parts. The head portion of this model has 246,831 elements and 71 parts, as shown in Figure 2 and 3. This model has been validated against number of cadaver experiments (Mao et al. 2013). Brain and ventricle pressure were validated from instrumented cadaver experiments (Nahum et al. 1977, Trosseille et al. 1992). Intracranial brain motion was validated using Hardy et al's experiments which tracked embedded neutral density targets in cadaver heads (Kleiven \& Hardy 2002, Hardy et al. 2008).

[Figure 2 and 3 near here]

The brain tissue including the cerebrum, cerebellum, corpus callosum, thalamus and brain stem are modelled as non-linear viscoelastic materials (Table 2). The viscoelastic materials are modelled using a Kelvin Maxwell model.

[Table 2 near here]

The simulations were performed by applying orthogonal linear acceleration components, and angular accelerations around each of the 3 axes, to the local co-ordinate system at the centre of gravity of the GHBMC head model. The simulations were run on LS-Dyna, Livermore Software Tech. Corp. for 50ms using Amazon Cloud Computing Services with 72 cores and 144Gbytes of memory. Simulations of $30 \mathrm{~ms}$ have been found to be insufficient as maximum strain may not been reached (Sanchez et al. 2019), thus 50ms was selected to enable the total strain to be recorded and yet have a reasonable simulation run-time of 4 hours. The first principal Green Lagrange strain was determined by locating the maximum within a region and averaging the strain around the adjacent elements, thus avoiding unrealistic singularities. The shear stress (Tresca) in the corpus callosum was found in a similar manner. The impact with the highest angular acceleration in each event was simulated. Simulation results were divided 
into the two categories; concussed and uninjured. The acceleration, strain and shear stress results in each category were then averaged.

\section{Statistical Analysis}

Descriptive statistics including means, standard deviations and t-tests were processed using MiniTab (Version 19.2020). A two sample independent t-test was used to compare concussive and uninjured data. The dependant variable was concussion/uninjured while the continuous variables were: resultant linear acceleration, resultant angular velocity, resultant angular acceleration, strain in the corpus callosum, thalamus, midbrain and brain stem, Tresca shear stress in the corpus callosum, and strain rate in the corpus callosum. A statistical significance of $\mathrm{p}<.05$ was used to reject the null hypthosis. Cohen's effect sizes were calculated to quantify the magnitude of the differences between the concussion injury data and the uninjured data. Cohen's number (d) defines the effect sizes as $d<0.01$ very small, $d<0.2$ small, $d<0.5$ medium, $\mathrm{d}<0.8$, large, $\mathrm{d}<1.2$ very large, and d $>2.0$ huge (Sawilowsky 2009).

\section{Results}

Data was recorded during 19 sparring sessions and 11 competitive events. Above 10g, 298 confirmed head impacts were recorded during the sparring sessions and 153 impacts at the competitive events. The average number of impacts above $10 \mathrm{~g}$ in the sparring sessions was 15.7. No injuries occurred during the sparring sessions. Five of the competitive events resulted in the fighter sustaining a concussion, all five fighters were professional or semi-professional and were in weight categories above $70 \mathrm{~kg}$. The concussions were diagnosed by a medical doctor either immediately after the event or at a 48 hour check-up. Symptoms reported included: a very short loss of consciousness ( $<1$ second), persistent headaches in the days following the event, visual disturbance and imbalance. The number of impacts in the events that ended with a concussion ranged from 4 to 26 . The average number of impacts that ended 
with a concussive impact was 16.0 while the average number of impacts in competitive events that had no injury was 12.2 .

A simulation was performed of the impact with the highest resultant angular acceleration from each of the 30 events. Maximum strain in the corpus callosum, thalamus, mid-brain, brain stem and overall (any brain region) were recorded from the simulations. Also recorded were the shear stress (Tresca), Von Mises distortion stress and strain rate within the corpus callosum. Maximum principal strain and stress results were averaged and are plotted in Figure 4 and 5.

[Figure 4 near here]

[Figure 5 near here]

The statistical differences between the concussed and uninjured athletes was investigated using independent sample t-tests (shown in Table 3). T-tests showed significant differences in the resultant linear acceleration, $\mathrm{t}(4)=2.9, \mathrm{p}<.05, \mathrm{~d}=1.4$ (very large effect size), strain in the corpus callosum $\mathrm{t}(4)=2.9, \mathrm{p}<.05, \mathrm{~d}=1.51$ (very large effect size), strain in the brain stem $\mathrm{t}(4)=2.8, \mathrm{p}<.05, \mathrm{~d}=1.49$ (very large effect size), and the Tresca shear stress in the corpus callosum $\mathrm{t}(5)=4.7, \mathrm{p}<.05, \mathrm{~d}=2.36$ (huge effect size). The effect size is quoted as per Sawilowsky 2009. There was no other significant difference between concussed and uninjured athletes in the resultant angular velocity, resultant angular acceleration, strain in the thalamus and mid brain, and the strain rate in the corpus callosum.

[Table 3 near here]

Figure 6 shows sample transverse and sagittal cross sections of the simulated brain strain of Fighter 5, Bout 1, impact 21 who was concussed. High strains are evident in the corpus callosum and thalamus. The high strains on the periphery of the brain are in the cerebrospinal fluid (CSF), hence they are not actual strains in the brain tissue. The strains in the CSF due to 
the fluid being modelled with solid elements with the bulk modulus of water. Figure 7 shows cross sections of an uninjured athlete (Fighter 10, Bout 1 impact 50).

[Figure 6 near here]

[Figure 7 near here]

\section{Discussion}

Head acceleration data was recorded from 451 video confirmed impacts in MMA at 30 events. This the only known study to measure head accelerations in vivo that have resulted in a concussive injury in an unhelmeted sport. The impact with the highest resultant angular acceleration from each event was simulated using the GHBMC head model. Linear accelerations to the side of the head (Y-direction) were $62.2 \%$ higher in impacts that resulted in a concussive injury. Punches to the jaw create high lateral accelerations and due to the offset from the co-ordinate system this leads to high angular accelerations about the $\mathrm{X}$-axis (coronal plane). Viano et al. studied boxers punching a Hybrid III head and found that 'hook' type punches lead to high moments about the $\mathrm{X}$-axis and very high angular accelerations (Viano et al. 2005). Impacts to the side of the head have been found to correlate with concussive injuries (Zhang et al. 2001, McIntosh et al. 2014, Hernandez et al. 2019).

In this study, linear acceleration, strain in the corpus callosum and brain stem and shear stress in the corpus callosum were significantly different $(\mathrm{p}<.05)$ between concussed and uninjured athletes. In this study, the strain in the corpus callosum differed by $87.9 \%(\mathrm{p}<.05)$ between concussed and uninjured athletes. This difference in strain in the corpus callosum was greater than any other brain region indicating that it may be the best strain indicator for concussion. The average strain in the corpus callosum of the concussed athletes in this study was 0.27 , this compares well with the strain of 0.3 found by Hernandez et al. in US football, although it should 
be noted that that study only included 2 cases of concussion (Hernandez et al. 2015). Newman et al reconstructed 58 impacts in US football and determined that the average linear and angular accelerations of concussed players was $97.8 \mathrm{~g}$ and $6432 \mathrm{rad} / \mathrm{s}^{2}$ (Newman et al. 2000, Newman et al. 2005). Kleiven simulated Newman's impacts and determined that the average strain in the corpus callosum of the concussed players was approximately 0.23 and predicted a $50 \%$ probability of concussion for strains of 0.21 (Kleiven 2007). Kleiven reported an average strain in the corpus callosum which was $28.6 \%$ lower than that found in this study but also reported an average angular acceleration which was $17.6 \%$ lower. Sanchez et al. found that there was an error in some of the accelerometer data in Newman et al.'s study which may have resulted in an average error in the maximum principal strain of $23 \%$.

In a simulation study of concussion in an unhelmeted sport, kinematic data from computer reconstructions were used to simulate impacts in Australian rugby and football (Patton et al. 2013). Patton et al. found that the average angular acceleration in concussive impacts was $7951 \mathrm{rad} / \mathrm{s}^{2}$ which is similar to the average angular acceleration of $7561 \mathrm{rad} / \mathrm{s}^{2}$ found in this study. Although the angular acceleration was similar Patton's average strain of $0.31 \pm 0.16$ in the corpus callosum was $14.8 \%$ higher than in this study. Patton et al's study had a wider spread of data than this study as indicated by his standard deviation of 0.16 . The greater spread of data in Patton's study may be due to the variation in magnitude and direction of impacts inherent in football as opposed to MMA and the methods employed in the re-creation of the impacts.

Tresca shear stress in the corpus callosum differed between concussed and uninjured athletes by $111.4 \%$ with a huge effect size (2.36) (Sawilowsky 2009). Indicating that shear stress, in this study, was the best parameter to predict a concussive injury, followed by the strain in the corpus callosum (1.51). Shear stress has been reported in very few studies of concussion. A US football study (Zhang et al. 2004) reported that the shear stress in the mid-brain was the best predictor of concussion. They found that shear stress in the thalamus differed by $58.5 \%$ 
between concussed and uninjured athletes, but they did not report on the magnitude of the shear stress in the corpus callosum.

\section{Conclusion}

This is the first known study to measure head accelerations in vivo in an unhelmeted sport, which included five concussions. The study found significant differences $(\mathrm{p}<.05)$ in the strain in the corpus callosum and brain stem of concussed athletes compared to uninjured. The magnitude of the strain in the corpus callosum was higher than in concussed athletes in a US football study due to a higher average angular acceleration. The single best predictor of concussion in this study was shear stress in the corpus callosum $(\mathrm{t}(5)=4.7, \mathrm{p}<.05, \mathrm{~d}=2.36)$. The high strains and shear stresses in the core brain regions were primarily due to lateral impacts which resulted in high angular accelerations in the coronal plane.

\section{Limitations}

The number of fighters and events in this study was limited; a greater number of impacts are required to improve the robustness of these findings. The mouthguard has been validated for indirect impacts but further validation is required for impacts directly to the sensors. Impacts that could not be video verified and also impacts that appeared to be direct hits to the mouthguard were removed; this may have resulted in some valid data not being included. The GHBMC head model has limitations inherent in finite element models and the material properties are approximations for brain tissue and assume homogeneous and isotropic behaviour. One of the criteria used to validate the GHBMC head model is relative brain-skull motion (Mao et al. 2013). Zhou et al. have suggested that this may not be sufficient for models intended for strain prediction (Zhou et al. 2018). 
The cerebrospinal fluid in the brain was modelled with solid elements with the bulk modulus of water. The concussed fighters received multiple impacts during their bouts therefore it is not possible to identify which impact caused the injury.

\section{Conflict of Interest}

The authors declare that they have no conflicts of interest.

\section{Funding}

This work was in part supported by CADFEM Ireland and UK Ltd.

\section{References}

Buse GJ. 2006. No holds barred sport fighting: A 10 year review of mixed martial arts competition. Br J Sports Med. 40(2):169-172.

Elliott MR, Margulies SS, Maltese MR, Arbogast KB. 2015. Accounting for sampling variability , injury under-reporting, and sensor error in concussion injury risk curves. $\mathrm{J}$ Biomech [Internet]. 48(12):3059-3065. http://dx.doi.org/10.1016/j.jbiomech.2015.07.026

Gennarellie T. 1983. Head injury in man and experimental animals: neuropathology. Acta Neurochir Suppl. 32:15-30.

Giordano C, Kleiven S. 2014. Evaluation of Axonal Strain as a Predictor for Mild Traumatic Brain Injuries Using Finite Element Modeling. Stapp Car Crash J. 58(14):29-61.

Hardy WN, Mason MJ, Foster CD, Shah CS, Kopacz JM, Yang H, King AI, Bishop J, Bey M. 2008. A study of the response of the human cadaver head to impact. Stapp Car Crash J. $51: 17-80$.

Hernandez F, Giordano C, Goubran M, Parivash S, Grant G, Zeineh M, Camarillo D. 2019. Lateral impacts correlate with falx cerebri displacement and corpus callosum trauma in sports-related concussions. Biomech Model Mechanobiol [Internet].(0123456789). https://doi.org/10.1007/s10237-018-01106-0

Hernandez F, Wu L, Yip MC, Laksari K, Hoffman AR, Lopez JR, Grant GA, Kleiven S, Camarillo D. 2015. Six Degree of Freedom Measurements of Human Mild Traumatic Brain Injury. Ann Biomed Eng. 43(8):1918-1934.

Ho J, Zhou Z, Li X, Kleiven S. 2017. The peculiar properties of the falx and tentorium in brain injury biomechanics. J Biomech [Internet]. 60(June):243-247.

http://dx.doi.org/10.1016/j.jbiomech.2017.06.023 
Holbourn AHS. 1943. Mechanics of Head Injuries. Lancet. 242(6267):438-441.

Hutchison MG, Lawrence DW, Cusimano MD, Schweizer TA. 2014. Head trauma in mixed martial arts. Am J Sports Med. 42(6):1352-1358.

King D, Hume P a, Brughelli M, Gissane C. 2014. Instrumented Mouthguard Acceleration Analyses for Head Impacts in Amateur Rugby Union Players Over a Season of Matches. Am J Sport Med [Internet]. ePub(ePub):ePub-ePub.

http://www.ncbi.nlm.nih.gov/pubmed/25535096

King D, Hume P, Gissane C, Brughelli M, Clark T. 2015. The Influence of Head Impact Threshold for Reporting Data in Contact and Collision Sports: Systematic Review and Original Data Analysis. Sport Med [Internet]. http://link.springer.com/10.1007/s40279-0150423-7

Kleiven S. 2005. Influence of direction and duration of impacts to the human head evaluated using the finite element method. Proc IRCOBI Conf Prague, Czech Repub [Internet].(September):41-57.

http://www.ircobi.org/wordpress/downloads/irc0111/2005/Session1/13.pdf

Kleiven S. 2007. Predictors for Traumatic Brain Injuries Evaluated through Accident Reconstructions. SAE Tech Pap [Internet]. 2007-Octob(October):81-114. http://www.ncbi.nlm.nih.gov/pubmed/18278592

Kleiven S, Hardy WN. 2002. Correlation of an FE Model of the Human Head with Local Brain Motion--Consequences for Injury Prediction. Stapp Car Crash J [Internet]. 46(November):123-144. http://www.ncbi.nlm.nih.gov/pubmed/17096222

Kuo C, Wu L, Hammoor BT, Luck JF, Cutcliffe HC, Lynall RC, Kait JR, Campbell KR, Mihalik JP, Bass CR, Camarillo D. 2016. Effect of the mandible on mouthguard measurements of head kinematics. J Biomech [Internet]. 49(9):1845-1853. http://dx.doi.org/10.1016/j.jbiomech.2016.04.017

Laksari K, Fanton M, Wu L, Nguyen T, Kurt M, Giordano C, Kelly E, O'Keeffe E, Wallace E, Doherty C, et al. 2019. Multi-directional dynamic model for traumatic brain injury detection. J Neurotrauma.:1-48.

Langlois JA, Rutland-Brown W, Wald MM, E T. 2006. The epidemiology and impact of traumatic brain injury: a brief overview. J Head Trauma Rehabil [Internet]. 21(5):375-8. http://www.ncbi.nlm.nih.gov/pubmed/16983222

Mao H, Zhang L, Jiang B, Genthikatti V V., Jin X, Zhu F, Makwana R, Gill A, Jandir G, Singh A, Yang KH. 2013. Development of a Finite Element Human Head Model Partially Validated With Thirty Five Experimental Cases. J Biomech Eng [Internet]. 135(11):111002. http://biomechanical.asmedigitalcollection.asme.org/article.aspx?doi=10.1115/1.4025101

McIntosh AS, Patton D a, Fréchède B, Pierré P-A, Ferry E, Barthels T. 2014. The biomechanics of concussion in unhelmeted football players in Australia: a case-control study. BMJ Open. 4(5):e005078.

Nahum AM, Smith R, Ward CC. 1977. Intracranial Pressure Dynamics During Head Impact [Internet]. http://papers.sae.org/770922/

Newman J, Barr C, Beusenberg M, Fournier E, Shewchenko N, Welbourne E, Withnall C. 
2000. A new biomechanical assessment of mild traumatic brain injury, part 2: results and conclusions. Proc 2000 Int Conf Biomech Impact.:223-233.

Newman J, Beusenberg MC, Shewchenko N, Withnall C, Fournier E. 2005. Verification of biomechanical methods employed in a comprehensive study of mild traumatic brain injury and the effectiveness of American football helmets. J Biomech. 38(7):1469-1481.

O’Keeffe E, Kelly E, Liu Y, Giordano C, Wallace E, Hynes M, Tiernan S, Meagher A, Greene C, Hughes S, et al. 2019. Dynamic blood brain barrier regulation in mild head trauma. J Neurotrauma.:1-27.

Ommaya AK, Gennarelli TA. 1974. Cerebral concussion and traumatic unconsciousness: Correlation of experimental and clinical observations on blunt head injuries. Brain. 97(4):633-654.

Patton DA, McIntosh AS, Kleiven S, E T. 2013. The Biomechanical Determinants of Concussion : Finite Element Simulations to Investigate Brain Tissue Deformations During Sporting Impacts to the Unprotected Head. J Appl Biomech. 29:721-730.

Raghupathi R, Mehr MF, Helfaer MA, Margulies SS. 2004. Traumatic Axonal Injury is Exacerbated following Repetitive Closed Head Injury in the Neonatal Pig. J Neurotrauma. 21(3):307-316.

Rowson S, Duma SM, Beckwith JG, Chu JJ, Greenwald RM, Crisco JJ, Brolinson PG, Duhaime A-C, McAllister TW, Maerlender AC. 2012. Rotational Head Kinematics in Football Impacts: An Injury Risk Function for Concussion. Ann Biomed Eng [Internet]. 40(1):1-13. http://link.springer.com/10.1007/s10439-011-0392-4

Sanchez EJ, Gabler LF, Good AB, Funk JR, Crandall JR, Panzer MB. 2019. A reanalysis of football impact reconstructions for head kinematics and finite element modeling. Clin Biomech. 64(February):82-89.

Sawilowsky SS. 2009. New Effect Size Rules of Thumb. J Mod Appl Stat Methods. 8(2):597-599.

Trosseille X, Tarriére C, Lavaste F, Guillon F, Domont A. 1992. Development of a F.E.M. of the human head according to a specific test protocol. SAE Tech Pap.

Viano, Casson I, Pellman E. 2005. Concussion in professional football: Brain responses by finite element analysis: Part 9. Neurosurgery. 57(5):891-915.

Viano D, Casson I, Pellman E, Bir C, Zhang L, Sherman D, Boitano M. 2005. Concussion in professional football: Comparison with boxing head impacts - Part 10. Neurosurgery. 57(6):1154-1170.

Wu L, Hernandez F, Kuo C, Kurt M. 2016. In Vivo Evaluation of Wearable Head Impact Sensors. Ann Biomed Eng. 44(4):1234-1245.

Zhang L, Yang K, King A. 2001. Comparison of brain responses between frontal and lateral impacts by finite element modeling. J Neurotrauma [Internet]. 18(1):21-30.

http://www.ncbi.nlm.nih.gov/entrez/query.fcgi? $\mathrm{cmd}=$ Retrieve $\& \mathrm{db}=\mathrm{PubMed} \& \mathrm{dopt}=\mathrm{Citation}$ \&list_uids $=11200247$

Zhang L, Yang K, King A, Viano D. 2003. A New Biomechanical Predictor for Traumatic 
Brain Injury - A Preliminary Finding. Proc 2003 Summer Bioeng Conf [Internet].(1):1-2. http://www.tulane.edu/ sbc2003/pdfdocs/0137.PDF

Zhang L, Yang KH, King AI. 2004. A Proposed Injury Threshold for Mild Traumatic Brain Injury. J Biomech Eng [Internet]. 126(2):226-236.

http://www.ncbi.nlm.nih.gov/entrez/query.fcgi?cmd=Retrieve \&db=PubMed\&dopt=Citation \&list_uids $=15179853$

Zhang, Yang K, King A. 2001. Recent advances in brain injury research: a new human head model development and validation. Stapp Car Crash J. 45(11):369-394.

Zhou Z, Li X, Kleiven S, Shah CS, Hardy WN. 2018. A Reanalysis of Experimental Brain Strain Data: Implication for Finite Element Head Model Validation. SAE Tech Pap. 2019Novem(November). 
Table 1: Study Participants

\begin{tabular}{|l|cc|c|c|cc|} 
& \multicolumn{2}{|c|}{ No. of Events } & & & & \\
& Sparring & Competition & Weight Class & Max Weight & Gender & Level \\
\hline Fighter 1 & & 1 & Lightweight & $70.3 \mathrm{~kg}$ & Male & Pro \\
Fighter 2 & 2 & 1 & Lightweight & $70.3 \mathrm{~kg}$ & Male & Pro \\
Fighter 3 & 3 & 2 & Middleweight & $83.9 \mathrm{~kg}$ & Male & Pro \\
Fighter 4 & 1 & 2 & Lightweight & $70.3 \mathrm{~kg}$ & Male & Pro \\
Fighter 5 & 4 & 1 & Lightweight & $70.3 \mathrm{~kg}$ & Male & Pro \\
Fighter 6 & 1 & 1 & Flyweight & $56.7 \mathrm{~kg}$ & Female & Pro \\
Fighter 7 & 1 & & Strawweight & $52.2 \mathrm{~kg}$ & Female & Pro \\
Fighter 8 & 1 & Bantamweight & $61.2 \mathrm{~kg}$ & Male & Amateur \\
Fighter 9 & 3 & 1 & Featherweight & $65.9 \mathrm{~kg}$ & Male & Pro \\
Fighter 10 & 1 & Bantamweight & $61.2 \mathrm{~kg}$ & Male & Semi - Pro \\
\hline Fighter 11 & 1 & 1 & Lightweight & $70.3 \mathrm{~kg}$ & Male & Semi-Pro \\
Fighter 12 & & 1 & Strawweight & $52.2 \mathrm{~kg}$ & Female & Pro \\
Fighter 13 & 1 & Welterweight & $77 \mathrm{~kg}$ & Male & Semi - Pro \\
\hline
\end{tabular}

Table 2: Material Properties of Principal Brain Parts

\begin{tabular}{|c|c|c|c|c|c|c|}
\hline \multirow[t]{2}{*}{ Description } & \multirow{2}{*}{$\begin{array}{l}\text { Number of } \\
\text { Elements }\end{array}$} & \multirow[t]{2}{*}{ Density } & \multirow{2}{*}{$\begin{array}{c}\text { Bulk } \\
\text { Modulus }\end{array}$} & \multicolumn{2}{|c|}{ Shear Modulus } & \multirow{2}{*}{$\begin{array}{c}\text { Decay } \\
\text { Constant }\end{array}$} \\
\hline & & & & Short term & Long term & \\
\hline & & $\rho$ & K & Go & $\mathrm{G}_{1}$ & \\
\hline & & $\left(\mathrm{kg} / \mathrm{m}^{3}\right)$ & (MPa) & $(\mathrm{kPa})$ & $(\mathrm{kPa})$ & $\mathrm{s}^{-1}$ \\
\hline Cerebellum Gray Matter \& Thalamus & 14540 & 1060 & 2190 & 3.00 & 0.60 & 200 \\
\hline Cerebrum, Mid-brain \& Brain Stem & 25484 & 1060 & 2190 & 6.00 & 0.60 & 200 \\
\hline Corpus Callosum & 980 & 1060 & 2190 & 3.75 & 0.75 & 200 \\
\hline Cerebrospinal Fluid & 10828 & 1040 & 2190 & 0.50 & 0.01 & 200 \\
\hline Cerebellum-White Matter & 23340 & 1060 & 2190 & 3.75 & 0.75 & 200 \\
\hline
\end{tabular}


Table 3: Results of statistical t-tests between concussed and uninjured athletes

\begin{tabular}{|c|c|c|c|c|c|c|c|c|c|}
\hline & 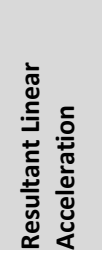 & 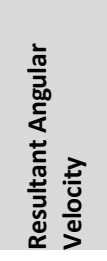 & 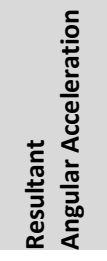 & 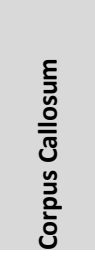 & 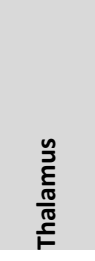 & 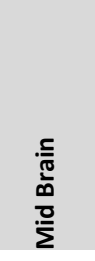 & 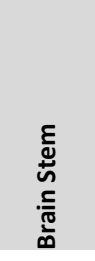 & 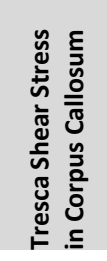 & 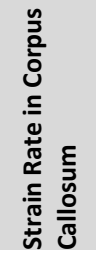 \\
\hline & (g) & $(\mathrm{rad} / \mathrm{s})$ & $\left(\mathrm{rad} / \mathrm{s}^{2}\right)$ & \multicolumn{4}{|c|}{ Strain } & $\mathrm{kPa}$ & $\mathrm{s}^{-1}$ \\
\hline $\begin{array}{l}\text { Competition concussed } \\
\text { Standard Deviation } \\
\text { concussed }\end{array}$ & $\begin{array}{l}86.7 \\
21.0\end{array}$ & $\begin{array}{l}24.0 \\
4.7\end{array}$ & $\begin{array}{l}7561 \\
1825\end{array}$ & $\begin{array}{l}0.27 \\
0.08\end{array}$ & $\begin{array}{l}0.24 \\
0.06\end{array}$ & $\begin{array}{l}0.27 \\
0.06\end{array}$ & $\begin{array}{l}0.25 \\
0.06\end{array}$ & $\begin{array}{l}16.87 \\
3.57\end{array}$ & $\begin{array}{l}54.40 \\
13.70\end{array}$ \\
\hline Average Uninjured & 56.8 & 13.6 & 5169 & 0.14 & 0.14 & 0.16 & 0.14 & 7.98 & 45.05 \\
\hline Standard Deviation uninjured & 21.6 & 10.7 & 3843 & 0.09 & 0.09 & 0.09 & 0.08 & 3.94 & 38.40 \\
\hline Difference in Averages & $52.7 \%$ & $76.7 \%$ & $46.3 \%$ & $87.9 \%$ & $75.0 \%$ & $68.1 \%$ & $71.2 \%$ & $111.4 \%$ & $20.8 \%$ \\
\hline T value & 2.9 & 2.1 & 1.4 & 2.9 & 2.5 & 2.5 & 2.8 & 4.7 & 0.5 \\
\hline p value & 0.034 & 0.1 & 0.245 & 0.033 & 0.066 & 0.067 & 0.049 & 0.005 & 0.619 \\
\hline Effect size (d) & 1.40 & 1.26 & 0.80 & 1.51 & 1.36 & 1.37 & 1.49 & 2.36 & 0.32 \\
\hline
\end{tabular}

NB: Significant differences $(\mathrm{p}<.05)$ are bolded 
Figure 1: The co-ordinate system and head and neck of the GHBMC model.

Figure 2: Brain parts in the GHBMC model

Figure 3: Sample data from sparring session

(Note: $3 \mathrm{~ms}$ pre trigger and $27 \mathrm{~ms}$ post trigger is displayed)

Figure 4: Average strains with standard deviation in various brain regions

Figure 5: Stress and strain rate with standard deviation in the corpus callosum

Figure 6: Transverse and Sagittal brain cross sections: Strain plots - Fighter 5 Bout 1 Impact 21 Concussed

Figure 7: Transverse and Sagittal brain cross sections: Strain - Fighter 10 Bout 1 Impact 50 Uninjured

NOTE:

Figure 3, 4, and 5 follow and are left in editable form. Figure 1, 2, 6 and 7 uploaded as separate files. 

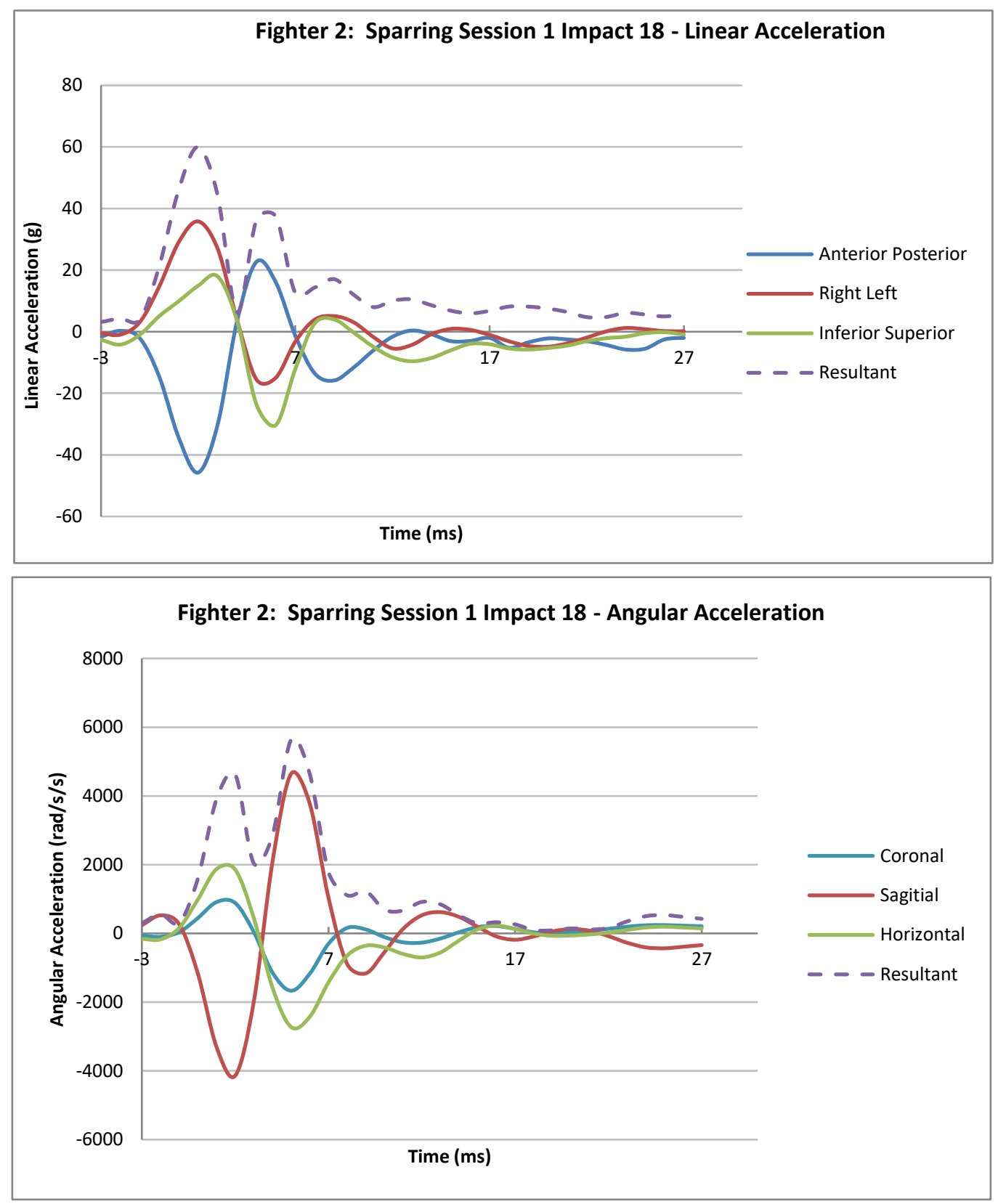

Figure 3: Sample data from sparring session

(Note: $3 \mathrm{~ms}$ pre trigger and $27 \mathrm{~ms}$ post trigger is displayed) 


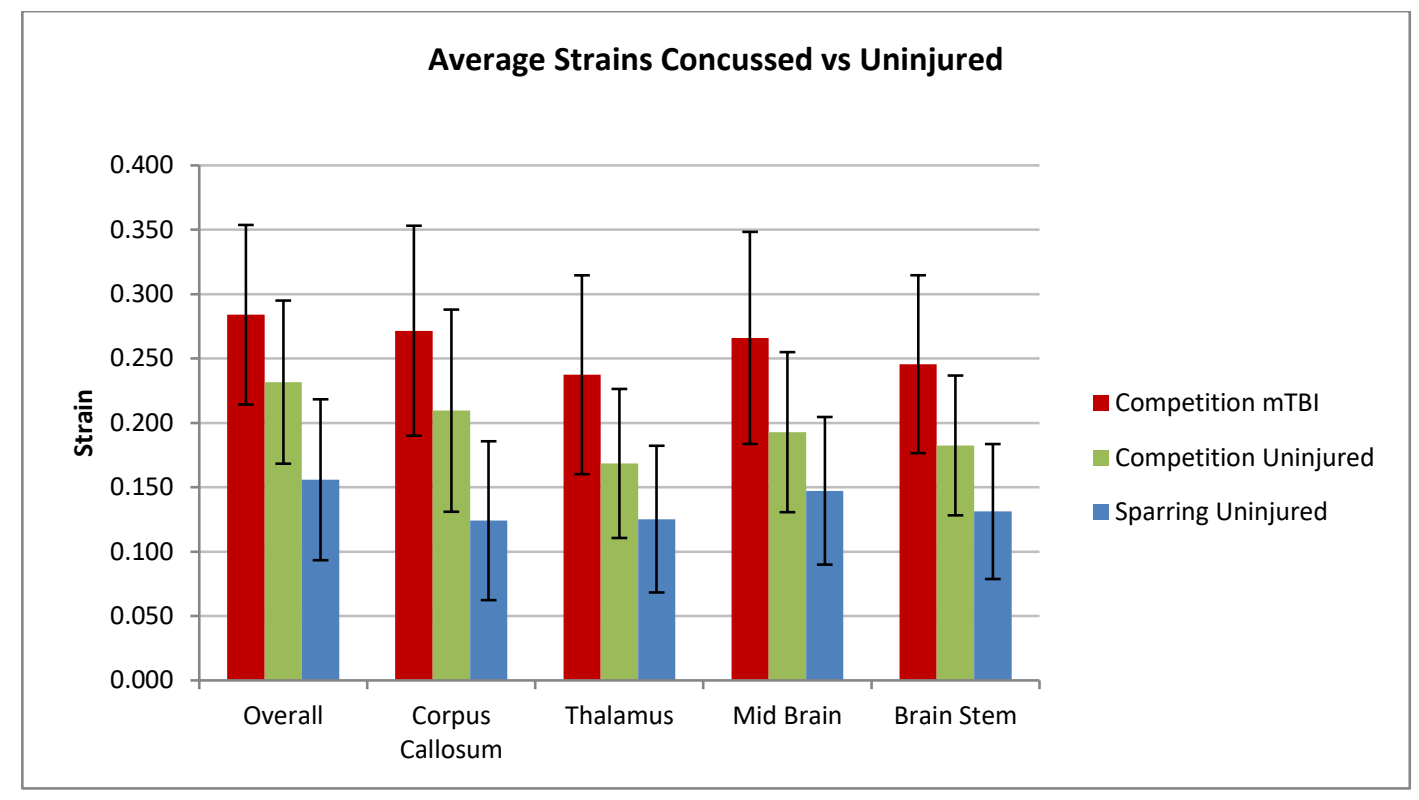

Figure 4: Average strains with standard deviation in various brain regions

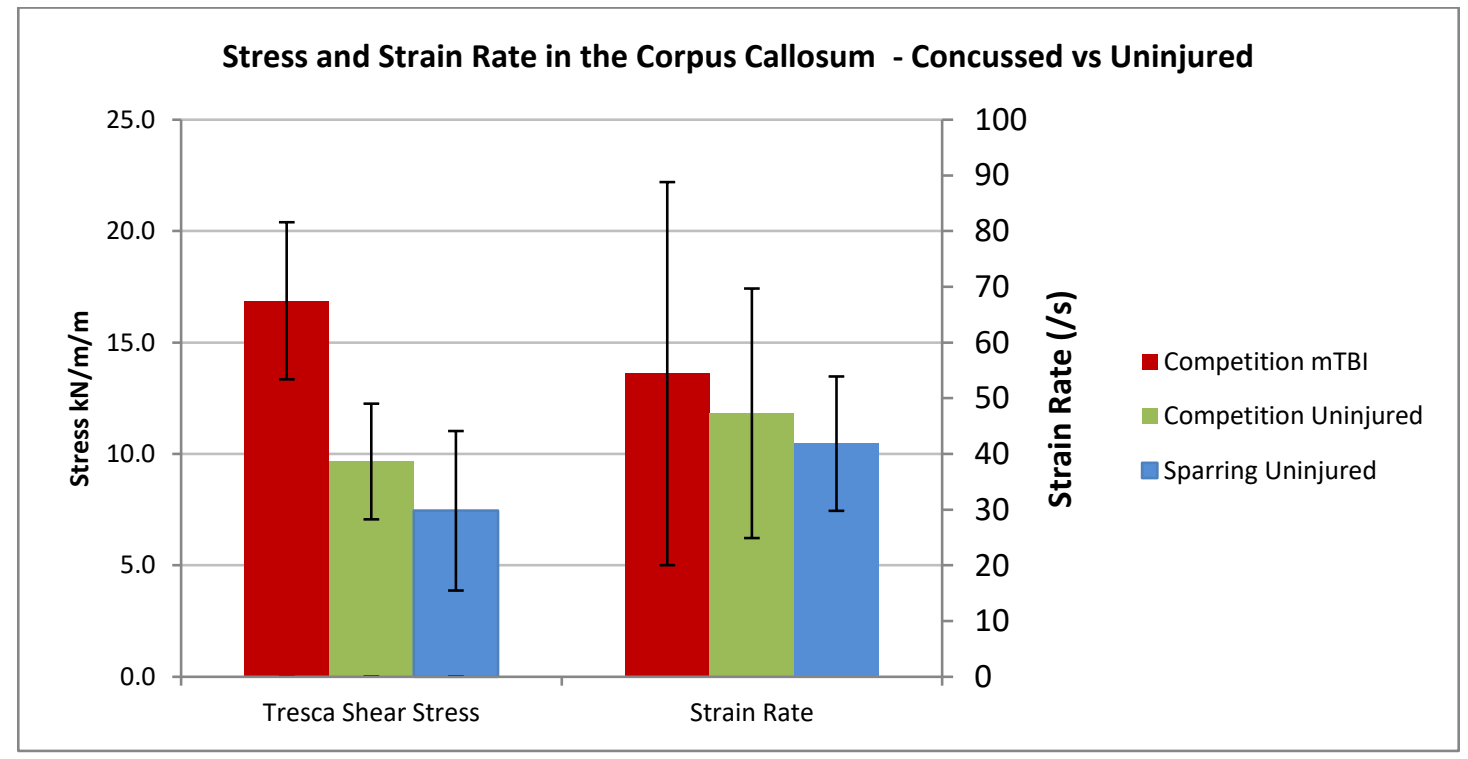

Figure 5: Stress and strain rate with standard deviation in the corpus callosum 